\title{
New Wave of Sexually-Transmitted HIV in Iran
}

\author{
Zahra Danial ${ }^{1}$, Malihe Sadat Moayed ${ }^{2 *}$, Mohammad Hossein Kalantar Motamedi', \\ Sedigheh Mirhashemi' ${ }^{1}$, Heshmatosadat Zamanian ${ }^{3}$ \\ ${ }^{1}$ Faculty of Trauma Research Center, Baqiyatallah University of Medical Sciences, Tehran, Iran \\ ${ }^{2}$ Faculty of Nursing, Baqiyatallah University of Medical Sciences, Tehran, Iran \\ ${ }^{3}$ Besharat School, Ministery of Educational and Development, Mashhad, Iran
}

*Corresponding Author: Malihe Sadat Moayed, Ph.D. Student in Nursing, Faculty of Nursing, Baqiyatallah University of

Medical Sciences, Tehran, Iran. Tel: +98-21-88053766, Fax: +98-21-88053766, Email: msmoayed@gmail.com

Received February 14, 2017; Accepted February 19, 2017; Online Published February 28, 2017

\section{Dear Editor,}

Despite advancements in medical science, the treatment of AIDS remains a public health problem, and the number of cases has been rising steadily in recent years. Although there is no consensus, statistics collected by the Universities of Medical Sciences and Health Services indicate that, as of 2012, a total of 27041 people with HIV/AIDS had been identified in Iran, $89.3 \%$ of whom were men and $10.7 \%$ were women. In 2009, 19774 people had been recognized. ${ }^{1}$ Statistics show that the third wave of AIDS continues until women are its silent victims. Addicts and their wives have also been afflicted as have their children, and this completes the cycle of disaster. The percentage of women who have contracted HIV infection from sexual relations has risen to $60 \% .^{2}$ Data shows that transmission through the sharing of injecting needles is $56 \%{ }^{3}$

Growth in the number of patients involved, the increasing number of drug users, the sharing of needles, increased sexual contact, the rise in the age of marriage, and increases in the divorce rate have caused the rate of sexually transmitted infections to rise. Evidence offers that in addition to the development of patients, the risk of transmission is driven by unprotected sexual contact. Programs to control and prevent HIV/AIDS and educate the public, with a special emphasis on prevention, are top priority. ${ }^{4}$ Stopping unprotected sex is of specific importance. Results of another study indicated that only $5.2 \%$ of female sex workers use a condom, and $90 \%$ of them are addicts. Drug users are sexually active and have multiple partners; thus, unprotected sex is quite common. More than $35 \%$ of addicts are married and $40 \%$ are not; $27 \%$ had more than 5 sexual partners. The rate of men who have had sex with other men at least once was reported to be $7 \%$ in prison and $67 \%$ outside of prison. ${ }^{5}$ Prostitutes and injecting addicts are very worrying. Based on studies, it is clear that the need for educational measures to raise public awareness and expertise in the field of AIDS prevention are warranted. This is particularly true for women who are victims of these new waves; the World Health Organization and the Joint United Nations Program on AIDS (UNAIDS) emphasized the fact that sexually transmitted diseases, one of the problems in society today, necessitates integrated health care that provides peer education, empowerment, promotion of condom use, and effective treatment of sexually transmitted diseases in high-risk groups such as female sex workers. ${ }^{6}$

Studies conducted to evaluate the awareness of women sex workers have shown that these women have information about AIDS, but because of financial need and addiction they do not use the information they have. Due to cultural constraints and hidden relationships, ${ }^{4}$ a comprehensive plan to prevent and detect HIV/AIDS and to promote the use of health services among members of this group is essential. Due to the growing HIV epidemic in this group of people, there is a possibility that a subsequent increase in cases may follow.

\section{Conflict of Interest Disclosures \\ None.}

\section{Authors' Contributions}

All authors have had an equal role in producing this article.

\section{Ethical Approval}

Not applicable.

\author{
Aknowledgments \\ The authors would like to thank the Clinical Research \\ Development Unit of Baqiyatallah Hospital for their kind \\ cooperation.

\footnotetext{
References

1. Solhi M, Haghighi M, Najarkolaei FR, Kashani HA, Zemestani AR. HIV prevention perception among barbers according to
} \\ health belief model (Persian). Journal of Research and Health.
}


2014:4(1):592-598

2. HIV/AIDS in Iran (Cumulative Statistics) (Persian). Iran: MoHME; 2013.

3. Mirzazadeh A, Haghdoost AA, Nedjat S, Navadeh S, McFarland W, Mohammad K. Accuracy of HIV-related risk behaviors reported by female sex workers, Iran: a method to quantify measurement bias in marginalized populations. AIDS Behav. 2013;17(2):623-631. doi:10.1007/s10461-012-0285-z.

4. Loraki M, Tafazoli M, Latifnejad Rodsari R, Shakeri MT, Babaie A. Assessment of perceived educational needs of damaged women in relation with high risk sexual behavior (Persian).
Iranian Journal of Obstetrics, Gynecology and Infertility. 2015;17(130):21-31.

5. Zamani S, Kihara M, Gouya MM, et al. High prevalence of HIV infection associated with incarceration among community-based injecting drug users in Tehran, Iran. J Acquir Immune Defic Syndr. 2006;42(3):342-346. doi:10.1097/01. qai.0000219785.81163.67.

6. Baral S, Beyrer C, Muessig K, et al. Burden of HIV among female sex workers in low-income and middle-income countries: a systematic review and meta-analysis. Lancet Infect Dis. 2012;12(7):538-549. doi:10.1016/S1473-3099(12)70066-X 